\title{
Influence of Strip Bite Time in Work Rolls Gap on Dynamic Loads in Strip Rolling Stands
}

\author{
Viktor Artiukh ${ }^{1, *}$, Vladlen Mazur ${ }^{2}$ and Elena Pokrovskaya ${ }^{3}$ \\ ${ }^{1}$ Peter the Great St. Petersburg Polytechnic University, Polytechnicheskaya, 29, Saint-Petersburg, \\ 195251, Russia \\ ${ }^{2}$ LLC “Saint-Petersburg Electrotechnical Company”, Pushkin, Parkovaya, 56, Saint-Petersburg, \\ 196603, Russia \\ ${ }^{3}$ Moscow State University of Civil Engineering, 129337, 26, Yaroslavskoye Shosse, Moscow, Russia
}

\begin{abstract}
Reasons of increase of dynamic coefficients of main drive lines are discussed. Methods of their calculation and technical solutions for their reduction are offered by means of increase of elastic torsion angle of main drive lines during unsteady rolling when metal bites happen. According to results of calculations of elastic shaft-energy accumulator it was recommended to install it in motor section of \#4A rolling stand of hot rolling mill 1700 of PJSC 'ILYICH iron and steel works' (Mariupol city, Ukraine).
\end{abstract}

\section{Introduction}

Productivity of rolling stands depend on speeds of their acting parts and minimal technological time. Due to it there is a 'speed problem' in rolling stands equipment design which is in constant solve with durability and stability of equipment [1]. To the point, reduction of dynamics in rolling stands is important for production of new flat products.

For characteristics of dynamic loads in rolling stands main drive lines dynamic coefficient is used $[2,3]$ :

$$
k_{d}=\frac{T_{d}}{T_{s t}}
$$

where $T_{d}$ is rolling torque during unsteady rolling, $N \cdot m$;

$\mathrm{T}_{\mathrm{st}}$ is rolling torque during steady rolling, $\mathrm{N} \cdot \mathrm{m}$.

Value of $k_{d}$ is not constant for single main drive line. It is proved that at bigger reduction of metal values of $k_{d}$ and $T_{d}$ are less compared to ones at smaller reductions. In addition, when width of strip is increased by 1.5 times $\mathrm{k}_{\mathrm{d}}$ increases by $10 \ldots 20 \%$. Also, it is important to consider:

- difference between speed of metal strip entering work rolls (WRs) gap and circumferential speed of WRs;

- values of radial gaps in elements of main drive lines;

\footnotetext{
${ }^{1}$ Corresponding author: artiukh@mail.ru
} 
- forms of front parts of metal sheet;

- time of metal strip bite $t_{b}$.

This paper is devoted to consideration of $t_{b}$ influence on increase of $T_{d}$.

For characteristics of work of metallurgical and rolling equipment a term 'Quality' $\mathrm{Q}$ is equal to technological load divided by maximum load. $\mathrm{Q}=0.50 \ldots 0.55$ during metal strip bite. It means that $\mathrm{k}_{\mathrm{d}}=$ const can be used for preliminary evaluation of dynamic loads acting in main drive lines during particular periods of time.

For calculation of maximum values of dynamic coefficients $k_{d}^{\prime}$ at interval $0.01 \mathrm{sec} \leq \mathrm{t}_{\mathrm{b}} \leq 0.03 \mathrm{sec}$ when radial gaps are closed it is reasonable to use method which was modified by authors of this paper by means of modern mathematical software and data given in particular scientific work reports :

$$
k_{d}^{\prime}=\lambda+\frac{A}{t_{b}},
$$

where $\lambda$ is a coefficient that takes into account dynamics due to $t_{b}$ during hot strip rolling and defined from graph on Fig. 1;

A is a coefficient that takes into account parametric characteristics of main drive line and its flexibility, sec.

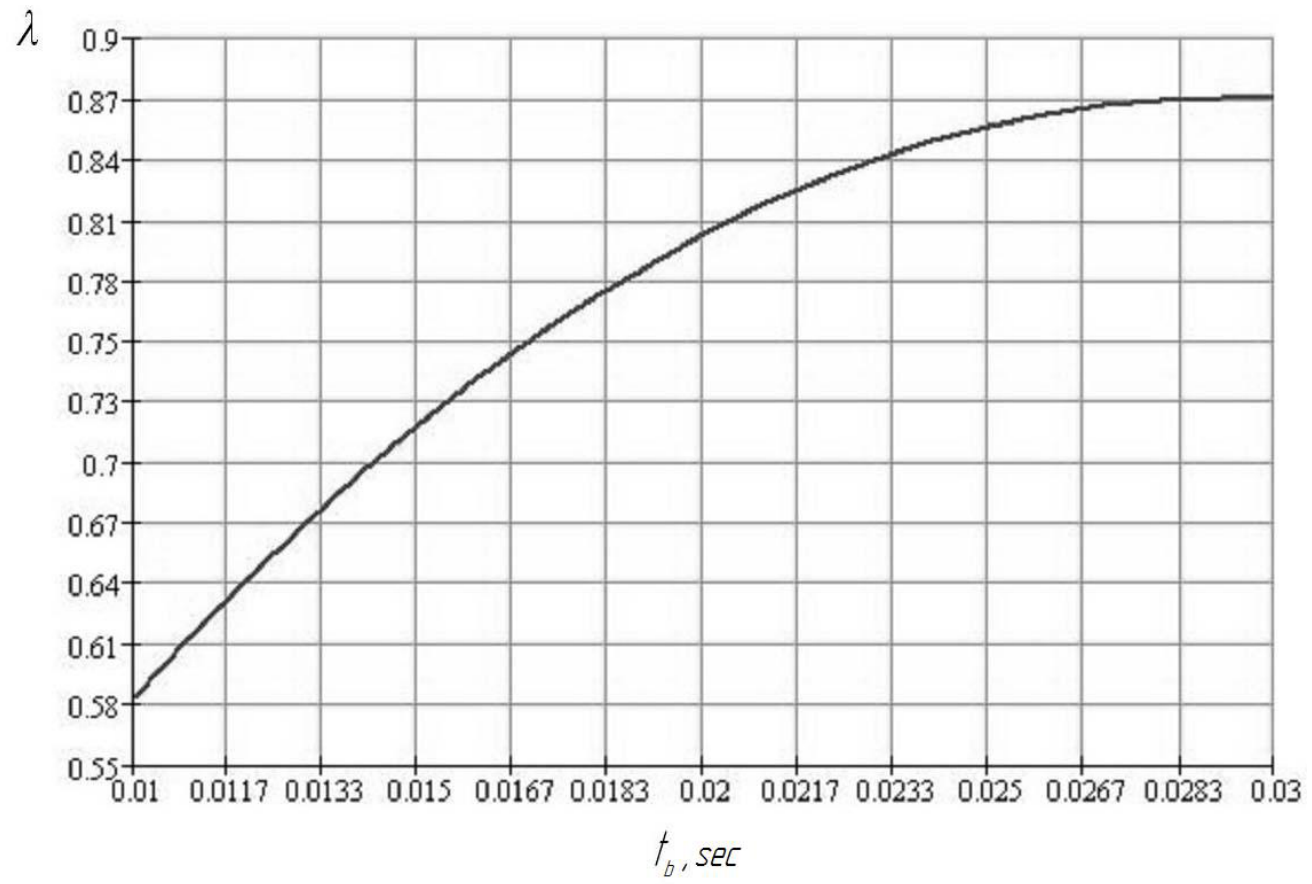

Fig. 1. Graph of coefficient definition which takes into account dynamics due to $t_{b}$

For approximate calculation of maximum value of dynamics coefficient $k_{d}^{\prime \prime}$ during thick sheet rolling at intervals $0.006 \mathrm{sec} \leq \mathrm{t}_{\mathrm{b}} \leq 0.5 \mathrm{sec}$ and $1.0 \leq \mathrm{k}_{\mathrm{d}} \leq 3.0$ it is reasonable to use method described as linear function, modified by authors of this paper:

$$
k_{d}^{\prime \prime}=1,8+m_{1} \cdot e-m_{2} \cdot t_{b}
$$


where $\mathrm{m}_{1}=0.3 \ldots 0.35 \mathrm{~mm}^{-1}$ is a coefficient that takes into account technological features of use of thick sheet rolling stands, $\mathrm{m}_{1}=0.3$ is for roughing rolling stands, $\mathrm{m}_{1}=0.35$ is for finishing rolling stands;

$\mathrm{e}$ is gap in main drive line within interval $0.0 \mathrm{~mm} \leq \mathrm{e} \leq 6.0 \mathrm{~mm}$ which opens and closes during metal strip bite by WRs, mm;

$\mathrm{m}_{2}=10 \ldots 20 \mathrm{sec}^{-1}$ is a coefficient that takes into account speed of metal strip bite by WRs; $\mathrm{m}_{2}=10$ is for high-speed main drive lines with speeds of metal strip bite equal to $2 \mathrm{~m} / \mathrm{s}$ and more, $\mathrm{m}_{2}=20$ is for low-speeds main drive lines (low speeds of metal strip bite by WRs).

Based on proposed methods of dynamics coefficients calculations at hot sheet/strip rolling it is possible to theoretically define dynamics coefficients relations to times of bites by WRs for different types of rolling stands. Initial data for calculation and its results are given in Tab. 1, where $k_{d}$ theor. is theoretically calculated dynamics coefficient at particular time of bite as per methods (2) and (3), $\mathrm{k}_{\mathrm{d} \text { exper. }}$ is experimentally calculated dynamics coefficient at particular time of bite, $\Delta$ is calculation error of $\mathrm{k}_{\mathrm{d} \text { theor. }}$.

Analysis of graphs of theoretical relation of dynamics coefficient and time of strip metal bite for main drive lines of different sheet rolling stands (refer to Fig. 2 - Fig. 6) and results of dynamics coefficients calculations bring us to conclusions:

- on practice, for preliminary calculation of elements and details of hot strip stands it is possible to use methods (2) and (3) because calculation error of $\mathrm{k}_{\mathrm{d} \text { theor. }}$ is not more than $5 \%$;

- according to theoretical calculation results, depending on type of rolling stand increase of time of metal bite by $30 \%$ can reduce dynamics coefficient by $5 \ldots 20 \%$; moreover, reduction of dynamics coefficient results in reduction of amplitude of $T_{d}$ oscillations at unsteady rolling that decreases thickness deviation of finish strip

Table 1. Initial data and results of theoretical calculations of relation between dynamics coefficient and time of metal strip bite

\begin{tabular}{|c|c|c|c|c|c|c|c|c|c|}
\hline Rolling stand & $\begin{array}{l}\mathrm{t}_{\mathrm{b}} \\
\mathrm{sec}\end{array}$ & $\mathrm{k}_{\mathrm{d}}$ theor & $\mathrm{A}, \mathrm{sec}$ & $k_{d}$ exper & $\begin{array}{c}\mathrm{m}_{1} \\
\mathrm{~mm}^{-1}\end{array}$ & $\begin{array}{c}\mathrm{e}, \\
\mathrm{mm}\end{array}$ & $\begin{array}{c}\mathrm{m}_{2}, \\
\mathrm{sec}^{-1}\end{array}$ & $\Delta, \%$ & $\mathrm{k}_{\mathrm{d}}\left(\mathrm{t}_{\mathrm{b}}\right)$ \\
\hline \multirow{2}{*}{$\begin{array}{l}\text { 750/350/750-800 3-Hi } \\
\text { rolling stand of JSC } \\
\text { 'Metallurgical Plant } \\
\text { 'Electrostal' } \\
\text { (Electrostal city, Russia) }\end{array}$} & $\begin{array}{c}0.01 \\
62 \\
\end{array}$ & 1.36 & 0.01 & 1.40 & & & & 2.85 & \multirow[b]{2}{*}{$\begin{array}{l}\text { Refer } \\
\text { to } \\
\text { Fig. } 2\end{array}$} \\
\hline & $\begin{array}{c}0.02 \\
3\end{array}$ & 1.28 & 0.01 & 1.26 & & & & 1.56 & \\
\hline $\begin{array}{l}\text { \#4A rolling stand of rolling } \\
\text { mill } 1700 \text { of PJSC 'ILYICH } \\
\text { iron and steel works' } \\
\text { (Mariupol city, Ukraine) }\end{array}$ & 0.02 & & 0.078 & 4.71 & & & & & $\begin{array}{l}\text { Refer } \\
\text { to } \\
\text { Fig. } 3\end{array}$ \\
\hline $\begin{array}{l}\text { \#1 rolling stand of rolling } \\
\text { mill } 1700 \text { of PJSC 'ILYICH } \\
\text { iron and steel works' }\end{array}$ & $\begin{array}{c}0.12 \\
8\end{array}$ & 2.26 & & 2.36 & 0.3 & 6.0 & 10.5 & 4.24 & $\begin{array}{l}\text { Refer } \\
\text { to } \\
\text { Fig. } 4 \\
\end{array}$ \\
\hline $\begin{array}{l}\text { Roughing stand of thick } \\
\text { sheet rolling mill } 3000 \text { of } \\
\text { PJSC 'ILYICH iron and } \\
\text { steel works' }\end{array}$ & $\begin{array}{c}0.05 \\
8\end{array}$ & 2.56 & & & 0.3 & 4.5 & 10.2 & & $\begin{array}{l}\text { Refer } \\
\text { to } \\
\text { Fig. } 5\end{array}$ \\
\hline $\begin{array}{l}\text { Finishing stand of thick } \\
\text { sheet rolling mill } 3000 \text { of } \\
\text { PJSC 'ILYICH iron and } \\
\text { steel works' }\end{array}$ & 0.04 & 2.55 & & & 0.35 & 3.3 & 10.0 & & $\begin{array}{l}\text { Refer } \\
\text { to } \\
\text { Fig. } 6\end{array}$ \\
\hline
\end{tabular}




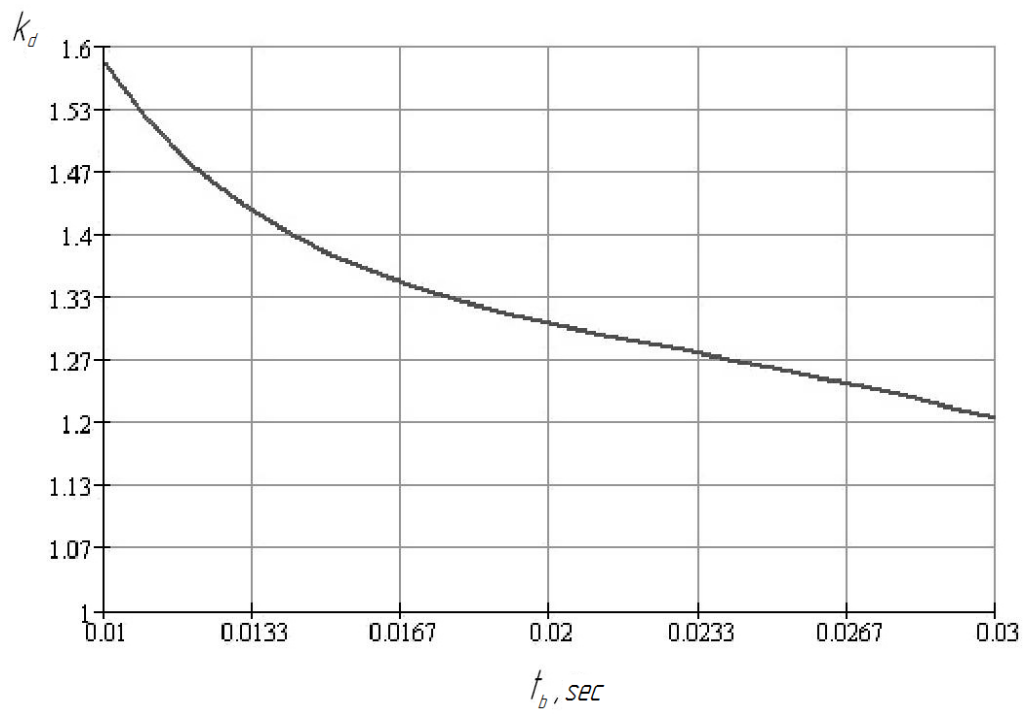

Fig. 2. Graph of relation between dynamics coefficient and time of metal strip bite for main drive line of 3-Hi rolling stand 750/350/750-800

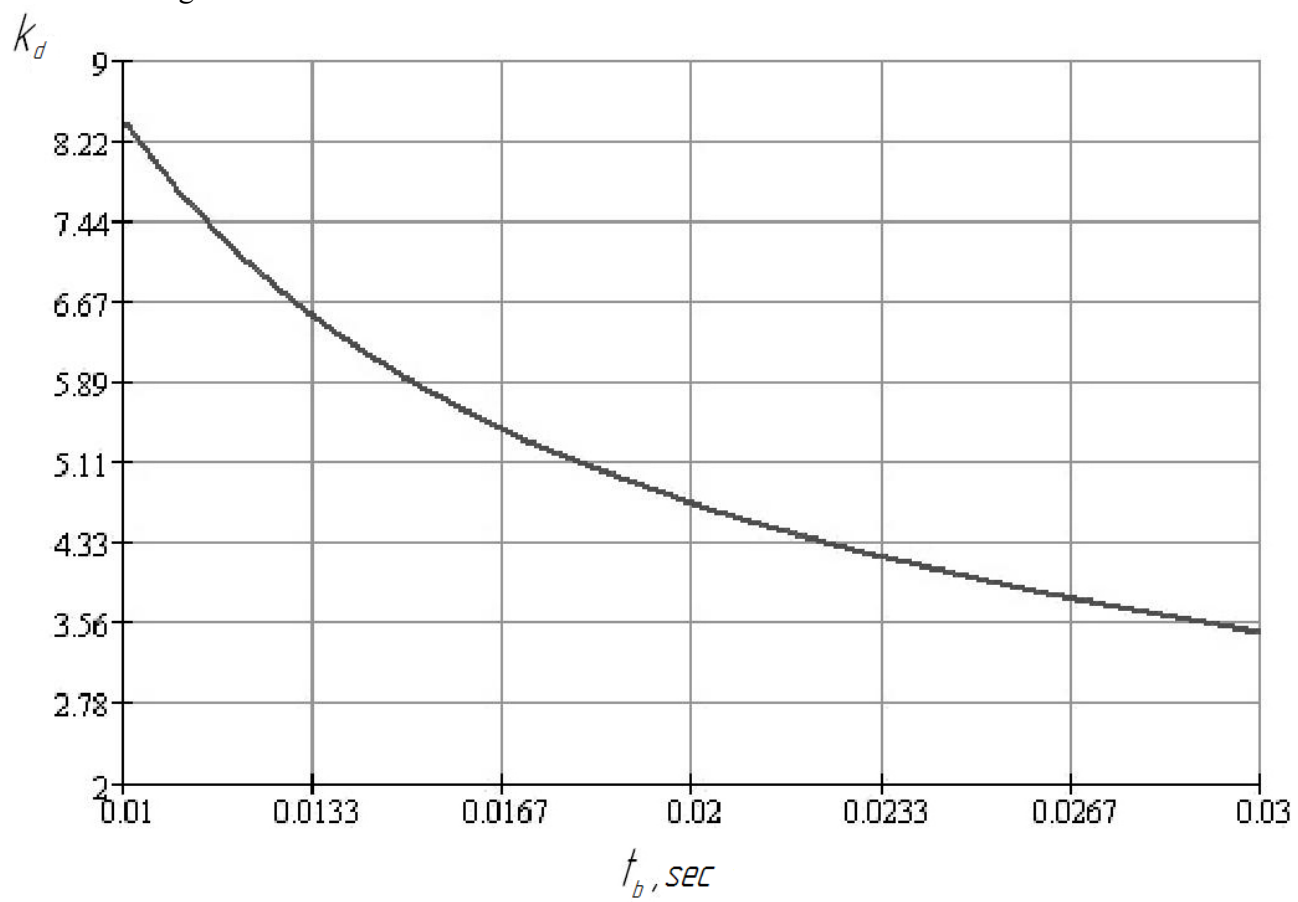

Fig. 3. Graph of relation between dynamics coefficient and time of metal strip bite for main drive line of rolling stand \#4A of rolling mill 1700 


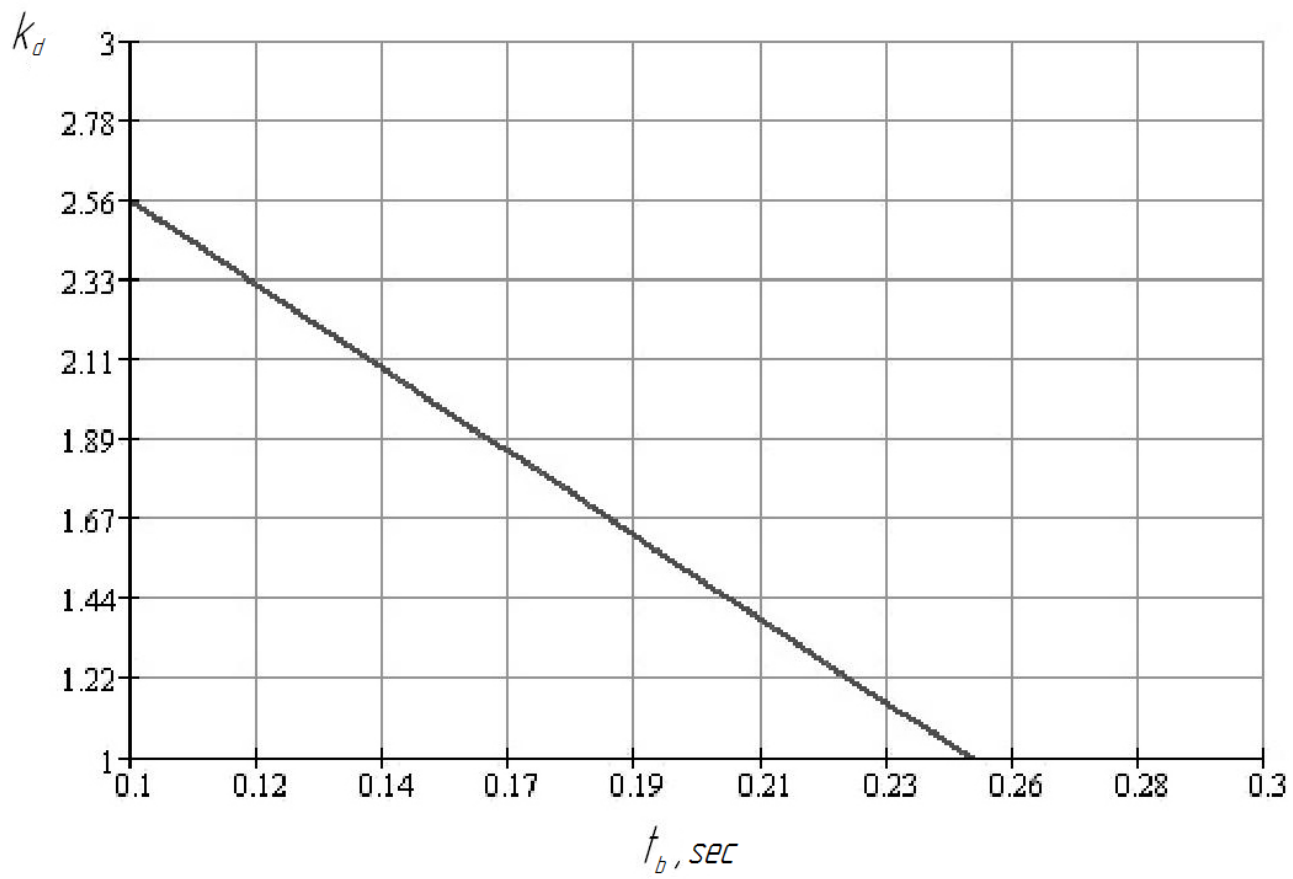

Fig. 4. Graph of relation between dynamics coefficient and time of metal strip bite for main drive line of rolling stand \#1 of rolling mill 1700

For reversing rolling stands where WRs are driven by DC motors there is a possibility to regulate speed of metal bite. For rolling stands where WRs are driven by synchronous AC motors there is possibility to regulate speed of metal bite by change of front form of metal sheet/strip. There are numerous proposals to make cuts of front form of metal sheets/strips by angular, chevron and trapezoidal contours. Experimental results of length evaluation of such contours within one rolling campaign on hot rolling mill 1680 of PJSC 'Zaporizhstal' (Zaporizhya city, Ukraine) after roughing group were $0.05 \ldots 0.2 \mathrm{~m}$ and after finishing group were $0.6 \ldots 1.5 \mathrm{~m}$. Similar experiments were done on roughing group of hot rolling mill 2000 of PJSC 'NLMK' (Lipetsk city, Russia) where dynamics coefficients were reduced by $8 \ldots 13 \%$ by usage of contours length equal to $0.22 \mathrm{~m}$. On practice method of use of angular, chevron and trapezoidal contours is not popular because of uniform further deformation (during reduction) of sheets/strips front parts.

Based on information given above authors of this paper propose new approach to increase time of metal bite by WRs and to reduce oscillations of $T_{d}$ by means of usage of flexibility of main drive line and increase of its energy capacity due to use of high-torque elastic shaft in main drive line and elastic shaft-energy accumulator which has elastic torsion angle $\varphi_{\text {oi }}$ (given to WRs) comparable to bite angle $\alpha_{0}$. WRs during metal bite will be rotating by angle (refer to Fig. 7): 


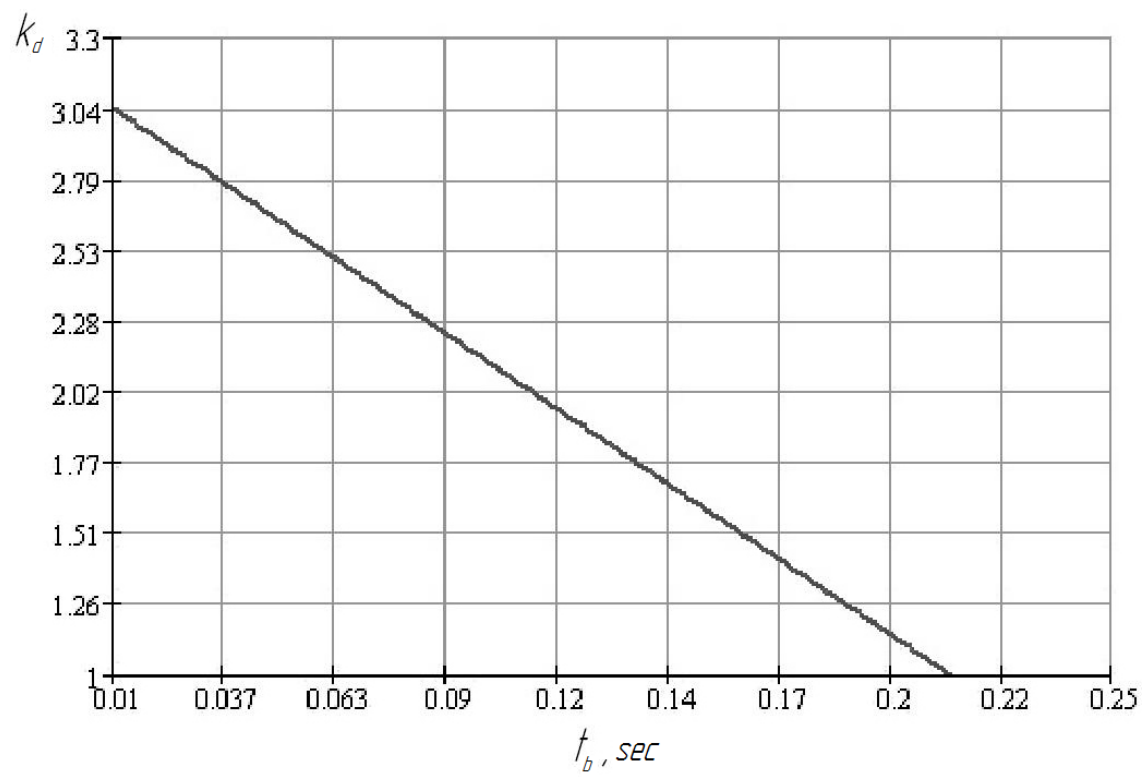

Fig. 5. Graph of relation between dynamics coefficient and time of metal bite for main drive line of roughing rolling stand of thick sheet rolling mill 3000

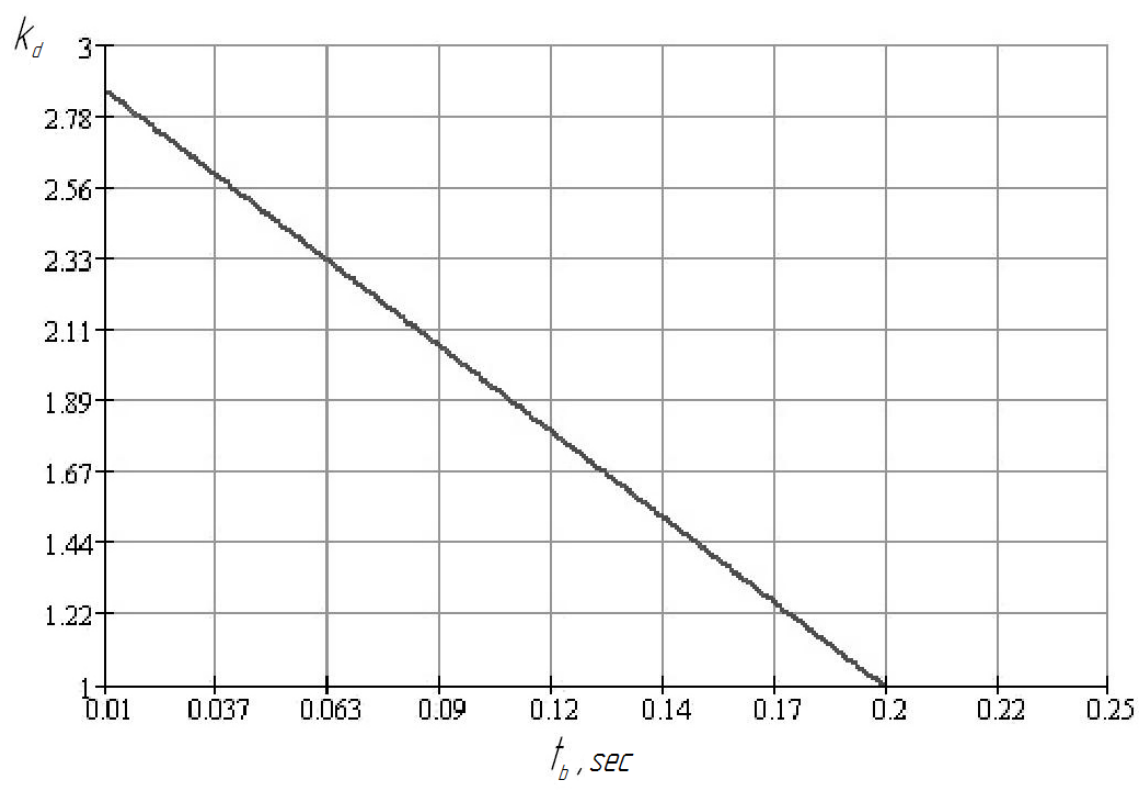

Fig. 6. Graph of relation between dynamics coefficient and time of metal bite for main drive line of finishing rolling stand of thick sheet rolling mill 3000

$$
\alpha=\alpha_{o}+\varphi_{\text {elast }}, \operatorname{deg}
$$

where $\varphi_{\text {elast }}$ is angle of elastic torsion of main drive line, deg. 


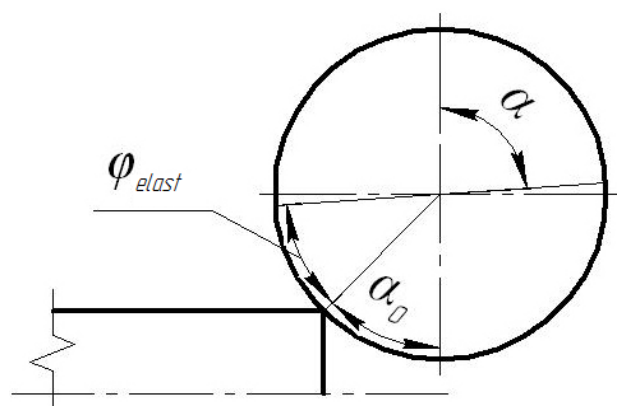

Fig. 7. Scheme of WR rotation angle calculation

Experimental measurements results of $T_{d}$ and $T_{s t}$ show that dynamics coefficients of motor sections mostly are higher than dynamics coefficients of spindle sections of main drive lines with reducer. It means that it is reasonable to install elastic energy-accumulator shaft in motor section.

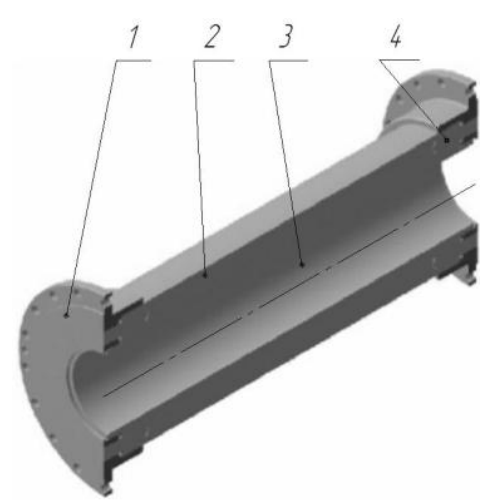

Fig. 8. General view of elastic shaft-energy accumulator: 1 - half-clutch; 2 - polyurethane elastic shaft element; 3 - cylindrical tube; 4 - pin.

Theoretical calculation shows that during steady rolling elastic shaft-energy accumulator (installed instead of initial shaft in motor section) has elastic torsion angle which does not significantly affect productivity of rolling stand.

Experimental shaft, which can provide dynamic rolling torque up to $250 \mathrm{kN} \cdot \mathrm{m}$ and torsion angle up to $180 \mathrm{deg}$ will be installed soon in the main drive line of hot strip rolling stand \#4A of rolling mill 1700 of PJSC 'ILYICH iron and steel works'. It is planned to increase metal bite time by 2 ...2.5 times due to usage of polyurethane elastic shaft element pos. 2 (refer to fig. 8) with damping coefficient equal to about 0.3 (was established experimentally). Moreover, damping can be significantly increased by usage of additional friction between polyurethane elastic shaft element pos. 2 and cylindrical tube pos. 3 .

FEM calculation results of elastic torsion angle of elastic shaft-energy accumulator during its loading by torque equal to $1 \mathrm{~N} \cdot \mathrm{m}$ are shown on Fig. 9, where UY states for movements (in meters) of particular points relative to axis Y. It means that when it comes to drive with $T_{d}=217 \mathrm{kN} \cdot \mathrm{m}$ [20] elastic torsion angle of elastic shaft-energy accumulator will be around $25.35 \mathrm{deg}$ and its value can be changed by changes in design of elastic shaftenergy accumulator and/or by usage of elastic shaft element made from another material. 


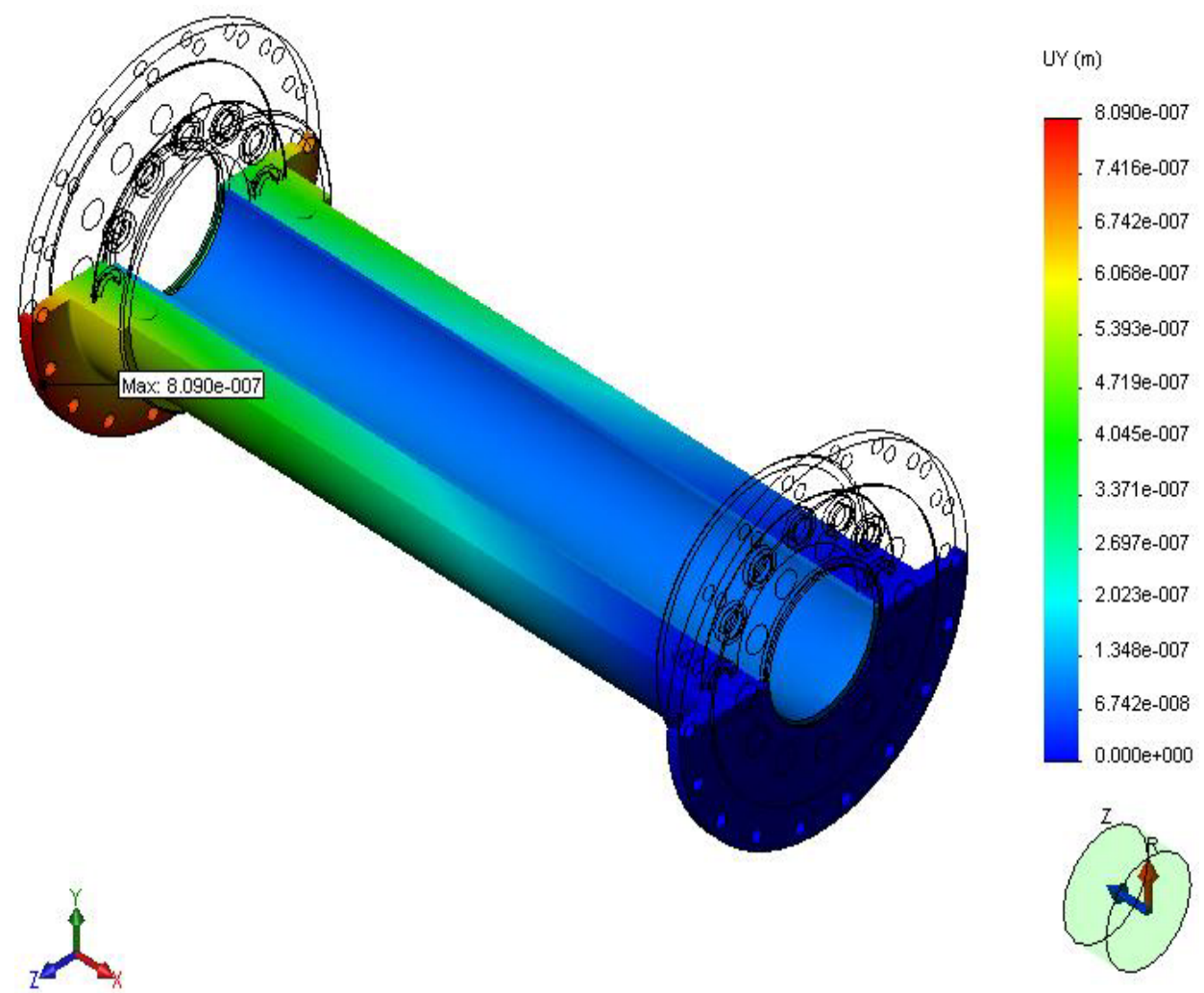

Fig. 9. FEM calculation results of elastic shaft-energy accumulator

The reported study was funded by RFBR according to the research project №16-0800845a «Verification and development of models of inelastic deformation at the passive loading». The authors declare that there is no conflict of interest regarding the publication of this paper.

\section{Conclusions}

1. Almost all hot sheet/strip rolling mills have low 'Quality' of their main drive lines that results in low durability and stability of their equipment.

2. One of main parameters which provokes inertia forces to arise during metal bite by WRs is time of metal bite which is reasonable to increase.

3. Theoretical methods of relation between dynamics coefficient and time of metal bite for main drive line are given.

4. Innovative approach to increase time of metal bite for main drive lines with synchronous AC motors is proposed.

\section{References}

1. E. Sorochan, V. Artiukh, B. Melnikov, T. Raimberdiyev. MATEC Web of Conferences, 73, 04009 (2016).

2. V. Artiukh, V. Mazur, R. Prakash. Solid State Phenomena, 871, pp. 3-8, (2016).

3. V. Mazur, V. Artyukh, G. Artyukh, M. Takadzhi. Eng. Designer, 37(1), 26-29 (2012) 